\title{
Impact of weather variation on feeding behaviour, nestling growth and brood survival in Wrynecks Jynx torquilla
}

\author{
Stephanie Geiser · Raphaël Arlettaz • \\ Michael Schaub
}

Received: 25 May 2007/Revised: 7 April 2008/Accepted: 14 April 2008/Published online: 15 May 2008

(C) Dt. Ornithologen-Gesellschaft e.V. 2008

\begin{abstract}
While habitat destruction is thought to be the most important reason for the decline of the Wryneck Jynx torquilla throughout Europe, it has been hypothesised that weather factors may also play a crucial role. We studied the impact of variations in ambient temperature and rainfall on feeding behaviour, nestling growth and daily brood survival probabilities in a population from the Swiss Alps. We recorded the frequency of food provisioning and measured nestlings' growth on 6 days at 17 nests, and monitored the success of 181 broods from 2002 to 2006 . The mean feeding frequency was 7.9 feedings per hour, and increased with temperature and with nestling age. Changes of body mass, tarsus length and of the 8th primary feather were not strongly influenced by temperature and rainfall. Body growth was negatively influenced by the initial size of the different body measures towards the end of the growing phase of the corresponding body measure, pointing towards compensatory growth. Daily brood survival probabilities declined in the course of the season and with increasing rainfall, and they increased with increasing temperature and with increasing nestling age. Our findings highlight
\end{abstract}

Communicated by T. Friedl.

Electronic supplementary material The online version of this article (doi:10.1007/s10336-008-0305-y) contains supplementary material, which is available to authorised users.

S. Geiser $\cdot$ R. Arlettaz $\cdot$ M. Schaub $(\bowtie)$

Conservation Biology, Zoological Institute,

University of Bern, Baltzerstrasse 6,

3012 Bern, Switzerland

e-mail: michael.schaub@nat.unibe.ch

R. Arlettaz $\cdot$ M. Schaub

Swiss Ornithological Institute, 6204 Sempach, Switzerland that the effects of adverse weather on feeding behaviour, nestling growth and nest survival in Wrynecks are complex, as they alter with the age of the nestlings and possibly with the duration of the adverse weather events.

Keywords Compensatory growth - Feeding frequency Nest survival $\cdot$ Temperature $\cdot$ Rainfall

\section{Introduction}

Variation of weather factors affects bird behaviour, population dynamics and distribution (Walther et al. 2002; Saether et al. 2003, 2004). Studies on the interaction of weather with birds are becoming increasingly important, because they would allow the prediction of the reaction of birds to global climate change. This in turn will allow to setting priorities for conservation, i.e. to rank species according to their sensitivity to climate change.

One of the main impacts of weather on population dynamics is variation of food availability: access to food resources is often impeded during adverse weather periods (e.g. Sæther et al. 2003; Schaub et al. 2005). In birds, food demand is highest when nestlings have to be reared; consequently reduced food availability during this period appears particularly critical affecting mainly reproductive output (Hafner et al. 1993; Nagy and Holmes 2004). The reproductive output influences in turn population growth according to the life history of the species under study. Populations of long-lived birds are not particularly sensitive to changes in reproductive output, while populations of short-lived birds are (Sæther and Bakke 2000). Populations of short-lived species are therefore expected to be sensitive to changes of food availability during the nestling period, and thus to weather variation during this period. 
The Wryneck Jynx torquilla has a wide Palearctic distribution and the populations in most European countries are declining (Tomialojc 1994). It is relatively short-lived (annual adult survival rates about 0.5; own unpublished data) and produces, on average, large but variable clutches with occasional second broods (Glutz von Blotzheim and Bauer 1980). Therefore, the dynamics of its populations are expected to be strongly dependent on reproductive output. The recognition of proximate factors impacting reproductive output is thus crucial for understanding population fluctuations, and interpreting the dramatic decline of Wrynecks over the past decades. The food during the breeding period consists almost entirely of broods of ground-dwelling ants (Menzel 1968; Hölzinger 1992; Bitz and Rohe 1993; Freitag 1996, 1998), and switching to other food types when ant availability is temporally reduced is unusual (Bitz and Rohe 1992). Ants move their brood vertically in the soil according to temperature and humidity in order to ensure their optimal development (Seifert 1996; Anderson and Munger 2003; Pranschke and Hooper-Bui 2003). When an ant brood is deep in the soil, access for the Wryneck is limited. It has been shown that periods with low temperatures and heavy rainfall result in a reduced nestling growth (Sutter 1941; Bitz and Rohe 1992, 1993), which led to the conclusion that Wryneck populations are especially sensitive to fluctuations of temperature and rainfall (Glutz von Blotzheim and Bauer 1980; Scherner 1989). However, this conclusion is based on a small number of surveyed broods (Sutter 1941; Bitz and Rohe 1992: one brood each) and generally only holds if slower nestling growth results in reduced reproductive output or recruitment. Knowledge about how quickly nestlings can make up for reduced growth (compensation) and about brood survival in relation to weather is therefore central to evaluate the impact of weather on Wryneck populations.

This study investigates the relationship between frequency of food provisioning by adults, nestling growth and brood survival, versus weather fluctuations during the breeding period. Thus, it focuses on the link between components of recruitment, to which Wryneck populations are expected to be sensitive, and weather fluctuations. First, we assessed variation of feeding frequency in relation to variation of temperature and rainfall, age and number of nestlings. Second, we tested whether the changes of body mass, lengths of tarsus and 8th primary feather over two successive days was affected by the average ambient temperature and amount of rainfall during these days. We also tested whether there was a negative relationship between the initial size of these three body measures and their growth rates in order to assess whether compensation in growth occurs. Lastly, we tested whether daily brood survival probabilities were related to weather factors.

\section{Materials and methods}

Study area

The study was carried out between 2002 and 2006 in the Upper Rhône Valley (Switzerland), between Vernayaz and Sierre around Sion $\left(46.2^{\circ} \mathrm{N}, 7.4^{\circ} \mathrm{E} ; 482 \mathrm{~m}\right.$ above sea level). The study area was $64 \mathrm{~km}^{2}(1.6 \times 40 \mathrm{~km})$. Fruit tree plantations and vineyards cover most of the intensively cultivated plain. In the vicinity of fruit tree plantations, 712 nest boxes were installed mostly in small agricultural cabins.

\section{Data collection}

During the years 2002-2006, all nest boxes within the study area were checked every fortnight with a mirror through the entrance hole. Nest boxes occupied by Wrynecks were checked every 3rd-5th day, allowing the recording of hatching dates. At each visit, the number of nestlings was counted and the fate of the brood was noted. Possible fates were still ongoing (at least one nestling alive), failed (all nestlings dead or depredated) and successfully fledged (i.e. at least one nestling has fledged). Based on these data, daily survival probabilities of the broods were estimated.

Data on nestling growth and feeding frequency were collected in 2004 from a random subset of all broods recorded in this year. We used a miniature camera that was fixed into the nest box roof and linked to a time-lapse video recorder to record feeding adult Wrynecks from dawn to dusk. The nestling period of Wrynecks lasts about 21 days (Glutz von Blotzheim and Bauer 1980). To obtain data from early and late nestling stages we recorded feeding frequency for the first time when the nestlings were 5 days old, and a second time when they were 14 days old. From the inspection of the videos, hourly feeding rates were calculated to test whether feeding frequencies change in response to weather within a day. Because the sex of the adults was unknown, we report the feeding frequencies that the brood is experiencing, and not the feeding frequency of a particular adult.

We recorded the body measurements from all nestlings of surveyed broods when they were 3, 5, 7, 12, 14 and 16 days old to obtain data from early and late nestling stages. We measured body mass $( \pm 0.1 \mathrm{~g})$, tarsus length $( \pm 0.1 \mathrm{~mm})$ and the length of the 8th primary feather $( \pm 0.5 \mathrm{~mm})$ always at 1200 hours. At the first measurement, each nestling was marked on its claws with red nail polish to allow individual identification. At the fourth or fifth measurement the nestlings were ringed with standard aluminium rings from the Swiss Ornithological Institute (Swiss Ringing Centre). 
We used temperature and rainfall data recorded in Sion by MeteoSwiss (Federal Office of Meteorology and Climatology), at a maximum distance of $25 \mathrm{~km}$ from the sampled Wryneck broods. For the brood survival analysis we used daily averages, for the nestling growth and feeding frequency analyses we used hourly records. Compared to the long-term average (1864-2006), the temperatures during the breeding period (May until July) in 2004 were slightly higher $\left(17.6^{\circ} \mathrm{C}\right.$ vs $\left.16.6 \pm 2.5^{\circ} \mathrm{C}\right)$, the amount of rainfall slightly lower $(118.5 \mathrm{~mm}$ vs $135.9 \pm 43.8 \mathrm{~mm})$, but both are well within the $95 \%$ confidence intervals. Hence, the year 2004 was slightly warmer and drier than the average, but not an unusual year.

\section{Statistical analyses}

\section{Food provisioning activity and nestling growth}

We analysed the impact of temperature, rainfall, age of nestlings and brood size on the feeding frequency with a generalised linear mixed model with a Poisson error distribution and a log link function. The dependent variable was the number of feedings per hour. The brood identity was considered as a random factor to avoid pseudo-replication. The fixed factors were brood size, age of the nestlings, hourly amount of rainfall, mean hourly temperature and its square. The latter was used to test for a possible curvilinear increase of the feeding frequency with temperature. We constructed 24 models which contained all possible combinations of the fixed factors. These models were ranked according to their support by the data by means of the Akaike Information Criterion (AIC) and the Akaike's weights (Burnham and Anderson 2002), and the smallest set of models whose cumulative sum of Akaike weights exceeded 0.95 (95\% confidence set of models) was identified. Based on the Akaike's weights, we then calculated for each fixed effect model averaged parameter estimates and the selection probability across the $95 \%$ confident set of models. The selection probability is the sum of the Akaike's weights from all models of the $95 \%$ confident set which include the focus fixed effect, and is equivalent to the probability that the focus fixed effect will appear in the AIC-best model.

To analyse the effect of temperature, rainfall, brood size and initial size of body measures on changes of body measures (i.e. nestling body mass, lengths of tarsus, and 8th primary), for each nestling we calculated the differences between measurements at age 3 and 5 days, between age 5 and 7 days, between age 12 and 14 days and between age 14 and 16 days, and performed separate analyses for these periods. We divided these differences by two to obtain daily growth rates. For each analysis, we used a linear mixed model with amount of rainfall, temperature (both calculated as the mean from all hourly values between the two consecutive measurements excluding the nights), brood size and size of each body measure at first measurement as fixed factors and a Gaussian error distribution. The brood identity was considered as a random factor to avoid pseudo-replication. Because tarsi were almost fully grown at an age of 12 days and primary feathers only start growing at an age of about 5 days (Fig. 3), we performed only two analyses for these two body measures at the ages when the traits were growing. Because some nestlings died and broods failed, sample sizes differed slightly between analyses. We applied the same procedure to rank the models, to identify the $95 \%$ confident set of models and to calculate model averaged parameter estimates as well as selection probabilities of the fixed effects as in the analysis of the feeding frequency. This time 16 models with all possible combinations of the fixed effects were used for each of the four independent variables.

All analyses were performed with $\mathrm{R}$ ( $\mathrm{R}$ Developing Core Team 2004), using the functions glmmML and lmer.

\section{Brood survival probability}

We estimated daily brood survival during the nestling period by an extension of the Mayfield method allowing the estimation of temporally varying daily survival rates (Dinsmore et al. 2002). This advanced brood survival model allows modelling the variation of daily brood survival probabilities as a function of daily varying environmental covariates. The data required for this model were (1) the day the brood was detected, (2) the last day the brood was checked and alive, (3) the last day the brood was checked, and (4) the fate of the brood (successful or not successful). To avoid pseudo-replication, we included only broods raised by individuals that bred for the first time in our study area. We defined a priori a set of biological hypotheses that we used to develop specific models to explain variation in brood survival of Wrynecks. We fitted these models and ranked them according to their support by the data by means of AIC. The hypotheses were as follows:

1. Year: annual variation can be a common source of variation in brood survival, and can result from factors such as changes in predator density or regional weather.

2. Time: the assumption of constant brood survival across season seems unrealistic since early broods are generally more successful than late broods (Dinsmore et al. 2002). Biological reasons may be the seasonal change of food availability or parental quality.

3. Age of the brood: the probability that a brood survives is likely to depend on its age, because the readiness of the adults to give up a brood due to short-term food 
shortage is likely to decline as brood ages and nestlings become more robust to short-term food shortage as they age. If this were true, brood survival would increase with brood age. We fitted models in which the brood survival was a linear function of the brood age.

4. Daily temperature and daily amount of rainfall: these two were the target variables to test whether brood survival was affected by weather variation. These factors could operate in conjunction on daily brood survival.

To reduce model space, we first modelled the factors that were not the main interest of our study (year, time, age). Then, we used the structure of the best of these models (time, age and year in our case) and added the mean daily temperature and daily amount of rainfall. All calculations were done with program MARK (White and Burnham 1999).

\section{Results}

Feeding frequency

We recorded 2,381 feedings during $299 \mathrm{~h}$ of video monitoring at 17 different broods aged either 5 or 14 days. In 12 broods, we could record the feeding frequency both when the nestlings were 5 and 14 days old. The overall mean $( \pm \mathrm{SE})$ feeding frequency per brood was $7.85( \pm 6.1)$ feedings per hour (range: $0-34$ ). The frequency distribution had two peaks at 1000-1200 hours and at about 1600 hours, the former being higher (Fig. 1). The mean hourly temperature measured on the video recording days showed a peak at about 1500-1600 hours (Fig. 1). The fixed factors temperature, its square and age of nestlings obtained a selection probability of 1 , whereas the brood

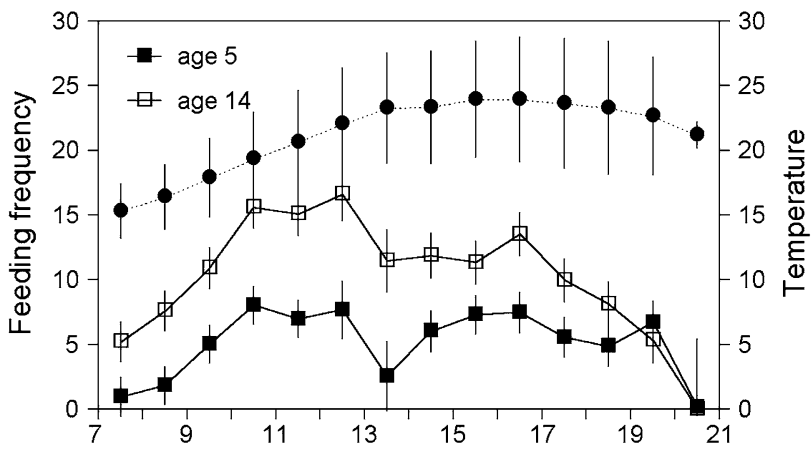

Fig. 1 Mean feeding frequency (number of feedings per hour) of Wrynecks Jynx torquilla in the course of the day when nestlings were 5 and 14 days old (closed and open squares) and mean hourly temperatures (closed dots) on the days when feeding frequency was recorded ( $n=20$ days) in central Valais 2004. Vertical lines show standard errors size and rainfall had a much lower selection probability and were therefore considered to be unimportant (Table 1, Appendix 1). Feeding frequencies increased with increasing temperatures up to about $25^{\circ} \mathrm{C}$ and then decreased again (Fig. 2). They also increased strongly with increasing age of the nestlings.

\section{Nestling growth}

The body mass increased rapidly until about day 12, thereafter the increase was much slower (Fig. 3a). Tarsi were already almost full-grown at an age of about 12 days (Fig. 3b). The 8th primary appeared at an age of 5-7 days, increased rapidly thereafter and were not fully-grown when the nestlings were 16 days old (Fig. 3c).

We measured growth of up to 107 nestlings from 15 different broods exposed to totally 34 different environmental conditions (different 2-day intervals). The mean temperatures during these intervals ranged from 14.6 to $27.5^{\circ} \mathrm{C}$ (mean: $20.5^{\circ} \mathrm{C}, \mathrm{SD} 3.2^{\circ} \mathrm{C}$ ), and the mean hourly amount of rainfall ranged from 0 to $0.67 \mathrm{~mm}$ (median $0 \mathrm{~mm}, 75 \%$ quantile $0.09 \mathrm{~mm}, 90 \%$ quantile $0.27 \mathrm{~mm}$ ). Our results regarding nestling growth in relation to weather are representative for these ranges.

Irrespective of the age of the nestlings, the change of body mass over 2 days did not depend on brood size (Table 2, Appendix 2), as evidenced by the low selection probabilities. Body mass change was negatively affected by initial body mass when nestlings were older than 12 days; thus, heavy nestlings grew more slowly than light nestlings. By contrast, initial body mass was positively related with body mass change when the nestlings young; thus, heavy nestlings grew faster than light nestlings.

Table 1 Model averaged mean (estimate), standard errors (SE) and selection probabilities of fixed effects on feeding frequency (number of feedings per hour) of Wrynecks Jynx torquilla in central Valais in 2004

\begin{tabular}{lrll}
\hline Fixed effect & Estimate & SE & Selection probability \\
\hline Intercept & -2.7540 & 0.5645 & \multicolumn{1}{l}{} \\
Rainfall & -0.0232 & 0.0517 & 0.324 \\
Temperature & 0.3831 & 0.0404 & 1.000 \\
Temperature $^{2}$ & -0.0084 & 0.0009 & 1.000 \\
Age of nestlings $_{\text {Brood size }}^{0.6182}$ & 0.0529 & 1.000 \\
\hline
\end{tabular}

Parameter estimates and SE were obtained by averaging all models from the $95 \%$ confidence model set constructed from originally 24 generalized linear mixed models with Poisson error distributions. The 24 models were formed with all possible combinations of the fixed factors rainfall, temperature, temperature ${ }^{2}$, age of nestlings and brood size. Temperature ${ }^{2}=$ Temperature $\times$ temperature (see Appendix 1). All models contained the random factor brood $[n=299 \mathrm{~h}$ from 17 broods; mean per brood $=17.6 \mathrm{~h}(\mathrm{SE} 7.1 \mathrm{~h})$ ] 


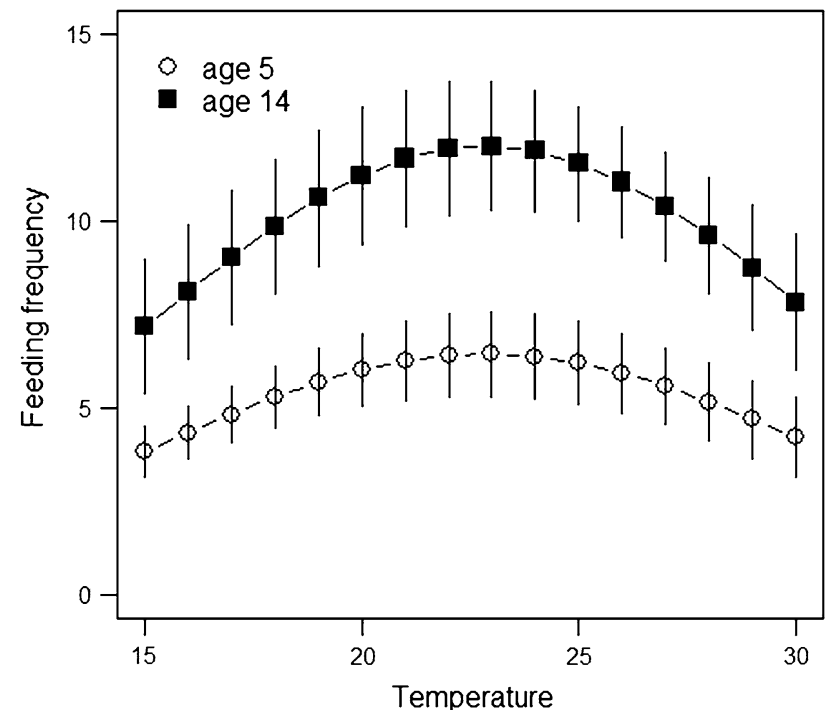

Fig. 2 Predicted mean number of feedings per hour at different temperatures and nestling ages based on model averaged parameter estimates in Table 1 recorded in central Valais in 2004. In all calculations, the brood size of 7.35 (mean value) and an amount of rainfall of $0 \mathrm{~mm}$ were used. Vertical lines show $95 \%$ confidence intervals

Temperature had no impact on body mass change in all ages but in the oldest one. Rainfall had an impact on the body mass change when the nestling were young, they grew slower with increasing amount of rainfall. Yet, the standard errors of the rainfall effect sizes were very large in all age classes indicating considerable uncertainty.

The changes of tarsus length were not affected by brood size, temperature and rainfall as evidenced by their low selection probabilities (Table 3, Appendix 3). The initial tarsus length had a negative impact on the growth, and the effect was stronger at age 5-7 days than when nestlings were younger. The changes of the 8th primary feather were not affected by brood size, and amount of rainfall (Table 3, Appendix 3). The initial length of the 8th primary feather had a positive effect on its growth at the age 12-14 days, but not later. In contrast to our expectations, growth of the 8th primary feather was negatively affected by temperature at age 14-16 days.

Daily brood survival during the nestling period

During the 5 years, we monitored 181 broods during the nestling period (altogether 2,696 days). Forty broods were not successful, of which seven were predated and the others abandoned. The first nestling hatched on 26 May and the last nestling fledged on 14 August. Thus, we modelled in total 80 daily survival rates in each year. The daily mean temperatures during these periods ranged from 8.9 to $27.5^{\circ} \mathrm{C}$ (mean $20.4^{\circ} \mathrm{C}, \mathrm{SD} 3.6^{\circ} \mathrm{C}$ ), and the daily amount of
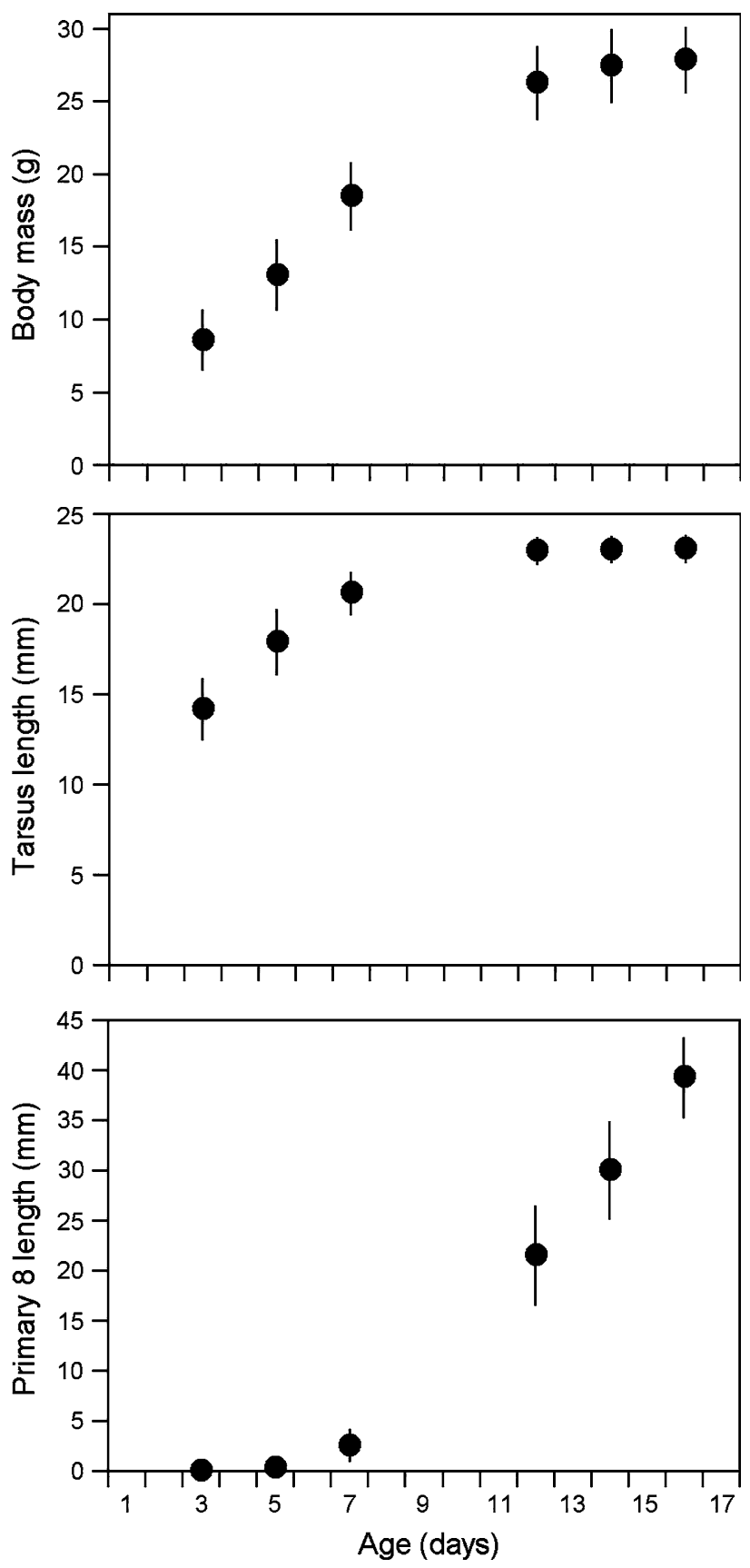

Fig. 3 Mean nestling body mass, tarsus length and length of 8th primary feather of Wrynecks at different nestling ages recorded in central Valais in 2004. Vertical lines show standard errors. Sample sizes: 432 nestlings from 11 nests

rainfall ranged from 0 to $34 \mathrm{~mm}$ (median $0 \mathrm{~mm}, 75 \%$ quantile $0.7 \mathrm{~mm}, 90 \%$ quantile $4.6 \mathrm{~mm}$ ).

Modelling the main effects (year, nest age, linear time trend) revealed that daily brood survival was affected by all main effects (Table 4). Daily brood survival decreased within season and increased with brood age (Fig. 4). The average (over the five study years) probability that a brood was successful (product of all daily brood survival 
Table 2 Model averaged mean (estimate), standard errors (SE) and selection probabilities (Sel. P) of the fixed effects brood size, initial body mass, mean hourly temperature, and mean hourly amount of rainfall on daily body mass changes (recorded during two consecutive days) of Wryneck nestlings at four different ages in central Valais in 2004 evaluated by mixed models

\begin{tabular}{|c|c|c|c|c|c|c|c|c|c|c|c|c|}
\hline \multirow[t]{2}{*}{ Factor } & \multicolumn{3}{|c|}{ Age $3-5$ days } & \multicolumn{3}{|c|}{ Age 5-7 days } & \multicolumn{3}{|c|}{ Age $12-14$ days } & \multicolumn{3}{|c|}{ Age $14-16$ days } \\
\hline & Estimate & SE & Sel. $P$ & Estimate & $\mathrm{SE}$ & Sel. $P$ & Estimate & SE & Sel. $P$ & Estimate & SE & Sel. $P$ \\
\hline Intercept & 2.500 & 1.539 & - & 2.565 & 0.842 & - & 5.052 & 1.814 & - & 5.879 & 2.326 & - \\
\hline Brood size & -0.013 & 0.042 & 0.269 & 0.016 & 0.038 & 0.289 & -0.026 & 0.069 & 0.282 & -0.052 & 0.073 & 0.473 \\
\hline Initial body mass & 0.065 & 0.031 & 0.930 & 0.003 & 0.010 & 0.255 & -0.151 & 0.028 & 1.000 & -0.118 & 0.027 & 1.000 \\
\hline Rainfall & -1.164 & 1.444 & 0.544 & -1.141 & 0.878 & 0.752 & 2.664 & 4.432 & 0.310 & -0.044 & 0.119 & 0.331 \\
\hline Temperature & -0.041 & 0.068 & 0.414 & 0.006 & 0.028 & 0.301 & -0.025 & 0.048 & 0.341 & -0.099 & 0.078 & 0.905 \\
\hline
\end{tabular}

Results were obtained by averaging all models from the 95\% confidence model set constructed from originally 16 linear mixed models with Gaussian error distributions. The 16 models were formed with all possible combinations of the fixed effects (Appendix 2). The random factor of the models was the brood. Sample sizes were $n=107$ nestlings from 15 broods (age 3-5 days), $n=104$ nestlings from 14 broods (age 57 days), $n=100$ nestlings from 14 broods (age 12-14 days), $n=90$ nestlings from 13 broods (age 14-16 days)

Table 3 Model averaged mean (estimate), standard errors (SE) and selection probabilities (Sel. P) of the fixed effects brood size, initial length of tarsus and 8th primary feather, mean hourly temperature, and mean hourly amount of rainfall on daily changes of tarsus length and of 8th primary feather length (recorded during two consecutive days) of Wryneck nestlings at four different ages in central Valais in 2004 evaluated by mixed models

\begin{tabular}{|c|c|c|c|c|c|c|c|c|c|c|c|c|}
\hline \multirow[b]{3}{*}{ Factor } & \multicolumn{6}{|c|}{ Tarsus length } & \multicolumn{6}{|c|}{ Length of 8th primary feather } \\
\hline & \multicolumn{3}{|c|}{ Age 3-5 days } & \multicolumn{3}{|c|}{ Age 5-7 days } & \multicolumn{3}{|c|}{ Age $12-14$ days } & \multicolumn{3}{|c|}{ Age $14-16$ days } \\
\hline & Estimate & SE & Sel. $P$ & Estimate & SE & Sel. $P$ & Estimate & SE & Sel. $P$ & Estimate & SE & Sel. $P$ \\
\hline Intercept & 2.767 & 1.137 & - & 4.152 & 0.512 & - & 3.409 & 2.025 & - & 8.507 & 3.396 & - \\
\hline Brood size & 0.014 & 0.033 & 0.270 & 0.003 & 0.017 & 0.249 & -0.089 & 0.139 & 0.408 & -0.007 & 0.045 & 0.275 \\
\hline Initial length & -0.026 & 0.035 & 0.720 & -0.161 & 0.024 & 1.000 & 0.018 & 0.022 & 0.711 & -0.003 & 0.007 & 0.361 \\
\hline Rainfall & -0.201 & 0.451 & 0.271 & 0.095 & 0.210 & 0.307 & 2.063 & 3.742 & 0.480 & -0.058 & 1.355 & 0.275 \\
\hline Temperature & -0.039 & 0.040 & 0.443 & 0.002 & 0.006 & 0.286 & 0.031 & 0.063 & 0.366 & -0.176 & 0.144 & 0.887 \\
\hline
\end{tabular}

Results were obtained by averaging all models from the $95 \%$ confidence model set constructed from originally 16 linear mixed models with Gaussian error distributions. The 16 models were formed with all possible combinations of the fixed effects (Appendix 3). The random factor of the models was the brood. Sample sizes were $n=107$ nestlings from 15 broods (age 3-5 days), $n=104$ nestlings from 14 broods (age 57 days), $n=100$ nestlings from 14 broods (age 12-14 days), $n=90$ nestlings from 13 broods (age 14-16 days)

probabilities from hatching to fledging) was 0.86 for the early broods (hatching date 26 May), 0.70 for the midseason broods (hatching date 24 June), and 0.43 for the late broods (hatching date 24 July).

The models including rainfall and temperature had better support than the best model without weather variables (Table 4). The amount of rainfall appears to be more important (selection probability of rainfall: 0.90 ) than the daily temperatures (selection probability of temperature: 0.48). The amount of rainfall had a negative (model averaged slope on the logit scale: -0.0790 , SE 0.0272) and the daily mean temperature a positive (model averaged slope on the logit scale: 0.0484 , SE 0.0665 ) effect on daily brood survival rate (Fig. 5).

In order to test whether complete nest failure was the main source of variation of the loss of nestling numbers during the nestling period, we inspected the number of hatched and fledged nestlings from 118 broods from 2002 to 2006, where these numbers were exactly known. From these broods, 853 hatchlings and 636 fledglings were recorded, resulting in an average nestling survival of 0.75 . The average nestling survival of successful broods (i.e. at least one nestling fledged, $n=94$ broods) was much higher (0.92). This shows that the complete nest failure was indeed the main source of variation for the loss of nestling numbers, and that the majority of successful broods could rear all nestlings.

\section{Discussion}

We provide evidence that temperature affected the food provisioning frequency of Wryneck parents, but most measures of nestling development were not affected by temperature. Rainfall neither had a strong impact on nestling development nor on the food provisioning frequency. However, variation of these two weather variables affected brood survival during the nestling period. Consequently, 
Table 4 Summary of model selection results for daily brood survival probabilities of Wrynecks during the nestling period in central Valais, 2002-2006

\begin{tabular}{lllll}
\hline Model & Deviance & $K$ & $\Delta \mathrm{AIC}_{\mathrm{c}}$ & $w_{\mathrm{i}}$ \\
\hline$S_{\text {year }+\mathrm{T}+\text { age }+ \text { rain }}$ & 278.69 & 8 & 0.00 & 0.46 \\
$S_{\text {year }+\mathrm{T}+\text { age }+ \text { temp }+ \text { rain }}$ & 276.74 & 9 & 0.06 & 0.44 \\
$S_{\text {year }+\mathrm{T}+\text { age }+ \text { temp }}$ & 283.47 & 8 & 4.78 & 0.04 \\
$S_{\text {year }+\mathrm{T}+\text { age }}$ & 285.85 & 7 & 5.14 & 0.03 \\
$S_{\mathrm{T}}+$ age & 294.85 & 3 & 6.11 & 0.02 \\
$S_{\text {year }+ \text { age }}$ & 295.84 & 6 & 13.13 & 0.00 \\
$S_{\text {age }}$ & 305.48 & 2 & 14.74 & 0.00 \\
$S_{\mathrm{T}+\text { year }}$ & 300.59 & 6 & 17.88 & 0.00 \\
$S_{\mathrm{T}}$ & 309.39 & 2 & 18.65 & 0.00 \\
$S_{\text {year }}$ & 305.40 & 5 & 20.68 & 0.00 \\
$S_{(.)}$ & 314.98 & 1 & 22.24 & 0.00 \\
\hline
\end{tabular}

For each model we show the deviance, the number of estimated parameters $(K)$, the difference of the small-sample size adjusted Akaike information criterion $\left(\mathrm{AIC}_{\mathrm{c}}\right)$ of the current model and the best one $\left(\Delta \mathrm{AIC}_{\mathrm{c}}\right)$, and the Akaike weight $\left[w_{\mathrm{i}}=\exp \left(-0.5 \times \Delta \mathrm{AIC}_{\mathrm{ci}}\right) /\right.$ $\left.\Sigma \exp \left(-0.5 \times \Delta \mathrm{AIC}_{\mathrm{c}}\right)\right]$. Notations: $S$ refers to the daily brood survival probability, and the subscripts to the way how $\mathrm{S}$ was modelled. $S_{(.)}$ single estimate of brood survival, $S_{T}$ linear time trend, $S_{\text {year }}$ effect of year, $S_{\text {age }}$ effect of age, $S_{\text {rain }}$ effect of daily amount of rainfall, $S_{\text {temp }}$ effect of daily mean temperature. A + indicates an additive effect of two or more variables on brood survival

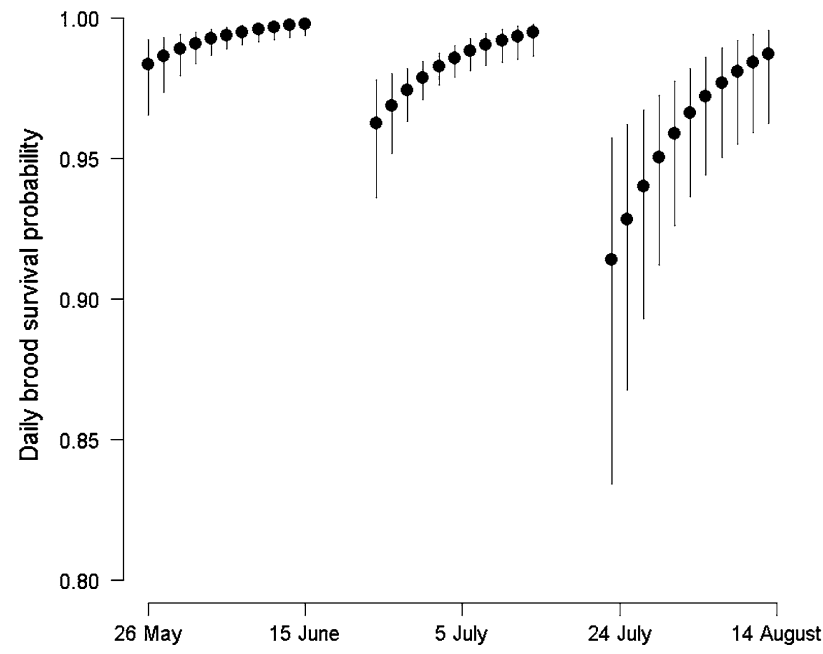

Fig. 4 Mean (over years) predicted daily brood survival rates and 95\% confidence limits for three hypothetical Wryneck broods that hatched at different dates based on data recorded in central Valais between 2002 and 2006. In the early season brood the nestlings hatched on 26 May, in the mid-season brood the nestling hatched on 24 June, and in the late season brood the hatching occurred on 24 July

weather variation during the breeding period potentially impacts Wryneck population dynamics.

The positive correlation of feeding frequency and temperature was likely a direct consequence of changes in food availability. The access to and the detection of the broods of ground-dwelling ants are best when the ant brood is kept near
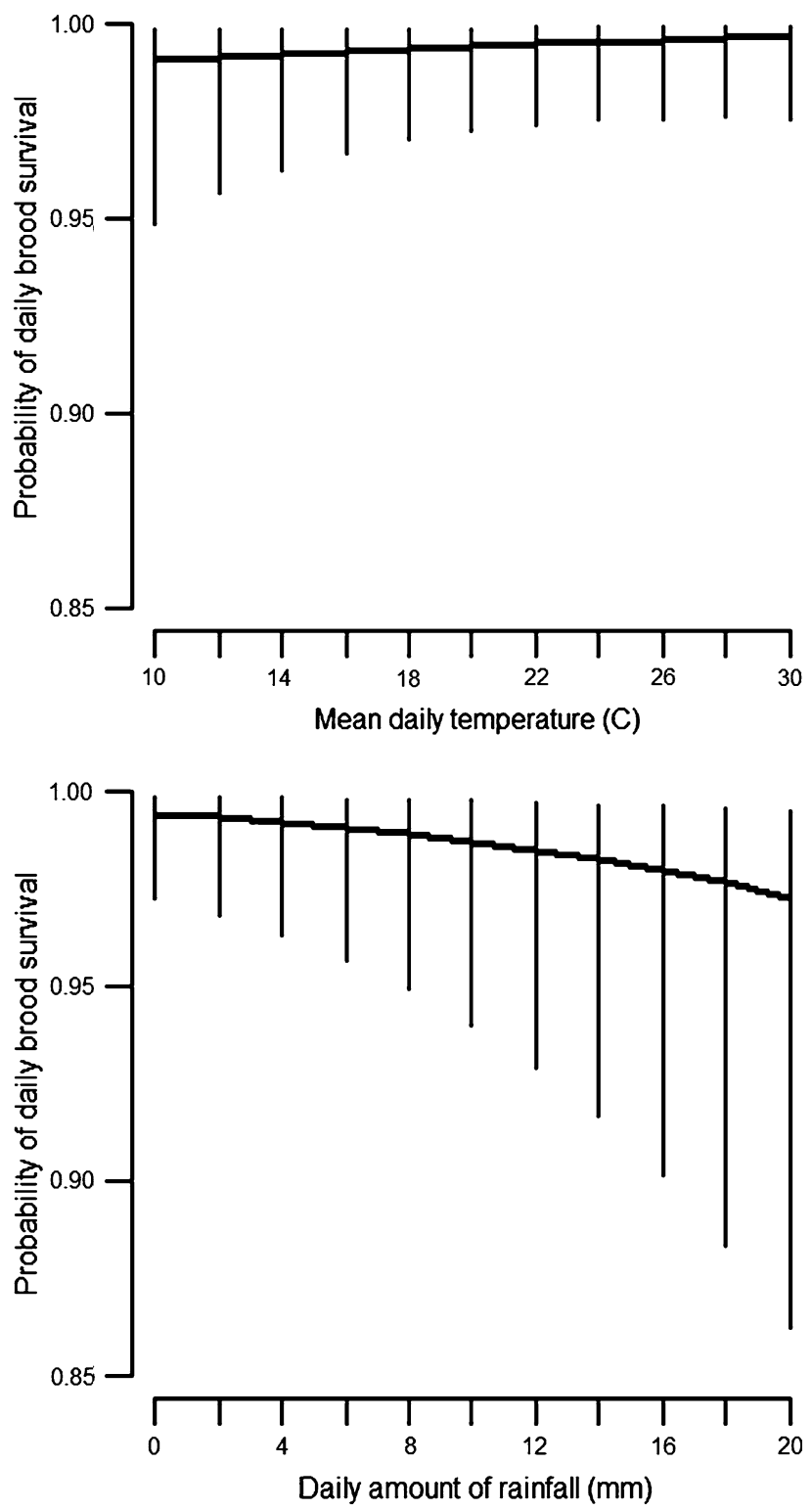

Fig. 5 Predicted model averaged daily survival probabilities of hypothetical Wryneck broods whose nestlings hatched on 26 May 2006 in relation to daily mean temperature and daily amount of rainfall based on data recorded in central Valais between 2002 and 2006. The vertical lines show the limits of the $95 \%$ confidence intervals

the soil surface, yet ant broods are deeper in the soil when temperatures are either too low or too high. This can explain why feeding rates followed a non-linear function with a peak at about $25^{\circ} \mathrm{C}$, as also observed in another study on Wrynecks (Freitag et al. 2001). The relationship between ant brood accessibility and rainfall is more difficult to interpret and our results are not fully conclusive. While ant broods need some humidity to develop properly, heavy rainfall may be disadvantageous because of low temperatures.

The parents could not only vary the amount of delivered food through the number of feedings, but also through the 
amount of delivered food per feeding event. Wrynecks are multiple prey loaders, i.e. they deliver several hundreds of prey items per feeding event (Bitz and Rohe 1993; Freitag 1998). Bitz and Rohe (1992) reported that the number of prey items per feeding event is dependent on weather. During adverse weather conditions (cold and rainy), an average feeding pellet contained only $61 \%$ of prey items compared to an average sample during favourable weather conditions. Hence, the difference of delivered biomass to nestlings between favourable and adverse weather periods would be more than estimated by the simple measurement of the variation of feeding frequencies alone, as in this study. If ants are not available during bad weather, Wrynecks may also feed on aphids (Menzel 1968). However, a change in prey selection according to weather is unlikely to be the rule (Bitz and Rohe 1992), and was not apparent in our study area. In 35 food pellets obtained with the ligature method from 22 broods in our study area in 2003 and 2004 during variable weather conditions, we only found aphids in one pellet (Ehrenbold 2004).

Nestling growth measured during 2 days was with few exceptions not influenced by the average temperature. In contrast to our expectations, changes of body mass and length of the 8th primary were negatively affected by temperature in the oldest nestling age. However, the standard error of this estimate was large and the negative relationship could largely be attributed to one brood. We therefore believe that temperature would not usually affect body mass change negatively. Body mass change was negatively affected by the amount of rainfall during the first nestling stages. Although this follows our expectations, the effect was very imprecisely estimated with large standard errors that challenge our finding. Generally, a larger sample size including data from several years may be necessary to get more conclusive results on the relationship between weather and Wryneck nestling growth. Other studies on insectivorous bird species often showed that adverse weather conditions and in particular rain are detrimental factors, reducing food availability on one hand and increasing energy demands of nestlings on the other (Keller and van Noordwijk 1994; Siikamäki 1996; Veistola et al. 1997; Radford et al. 2001). In this study, Wryneck nestling growth measured during 2 days was not strongly influenced by the average temperature and rainfall during this time period. This does not, however, mean that Wryneck nestling growth is completely independent on prevailing weather conditions. Bitz and Rohe (1992) found short-term effects of weather in a Wryneck brood: low temperatures and rainfall negatively affected nestling growth measured over 1 day. If this result from one brood can be generalised, it appears that Wryneck nestling growth is reduced during adverse weather conditions as food provisioning by the adults is reduced. If the weather conditions improve and hence food provisioning increases, nestlings are able to catch up with growth quickly. Therefore, the impact of weather on growth measured over longer periods may no longer be apparent. It is currently not known for how long adverse weather conditions can prevail until deleterious effects on Wryneck nestlings occur.

The growth rates of the nestlings were independent from brood sizes. This may indicate that adults are adjusting their clutch size in relation to the capacity of their territory in such a way that the development of the nestlings is independent from brood size, in line with the idea of an optimal clutch size (Stearns 1992). The growth rates of body mass at the older nestling stage and of tarsus length were negatively influenced by their initial sizes, which shows that the ability for growth compensation after reduced growth is well established in Wrynecks. This agrees with the observation by Sutter (1941) who described how a nestling weighing $24.8 \mathrm{~g}$ that lost $6.2 \mathrm{~g}$ during 2 days was able to compensate for this loss after a few days. Compensation of body mass was not apparent when the nestlings were young suggesting that factors resulting in reduced nestling growth may have more importance when occurring in the early nestling stages than when occurring later. The capability to compensate growth can help to overcome negative effects of short-term weather fluctuations, but it does not appear to be common in most altricial birds (Lepczyk and Karasov 2000).

Daily brood survival probabilities increased with increasing daily temperatures and decreased with increasing amount of rainfall. The effect of temperature on daily nest survival appears to be less strong than the effect of rainfall. Based on our estimates, a $0.5 \%$ decline in daily nest survival probability requires a temperature decline by about $12^{\circ} \mathrm{C}$ or about $8 \mathrm{~mm}$ rain within a day. Such weather changes are not occurring frequently: the $90 \%$ quantile of temperature spans only $11^{\circ} \mathrm{C}$ and in only $7 \%$ of all days the amount of rain was more than $8 \mathrm{~mm}$. Still, a $0.5 \%$ decline of daily survival would transfer into a $9 \%$ decline of brood survival and thus would be considerable.

Does our study provide evidence that variation of weather factors during the breeding period has an impact on the population dynamics of Wrynecks? We expect that Wryneck population dynamics are sensitive to changes in recruitment (Sæther and Bakke 2000), and consequently factors that affect recruitment have an important impact on population dynamics. We showed that the observed weather variation affected brood survival and feeding frequencies, but had limited impact on nestling growth measured over short time periods. Since brood survival is reduced when weather conditions are unfavourable, it ultimately means that nestlings die under these conditions. With increasing age nestlings became able to compensate 
growth and probably less sensitive to unfavourable weather conditions. Consequently, the daily nest survival probabilities increased with age. This highlights that the effects of adverse weather conditions on reproduction and finally on population dynamics are complex, since the strength of impact likely changes with nestling age and possibly also with the duration of the adverse weather conditions. Other elements of recruitment not studied here such as brood initiation, clutch size or post-fledging survival might be affected in addition by weather conditions.

Wrynecks reduce feeding activity during bad weather at the expense of a short-term slower nestling growth (Bitz and Rohe 1992). Under good weather circumstances feeding activity is increased substantially, and nestlings have a good ability to recover development unless they are too old. The compensatory nestling growth strategy may only be successful if the reduced food availability does not last for too long and if food availability is temporally unlimited. Reduced abundance of ants due to habitat degradation is expected to be particularly deleterious for populations at places where cold spells are more frequent and longer than in our study area. Marginal populations are expected to fluctuate more strongly, due to higher weather variation, and to have higher local extinction risks than populations in core distribution areas. It is therefore not surprising that range contractions and severe population declines occurred first in $\mathrm{N}$ and NW Europe where Atlantic climate dominates (Monk 1963; Tomialojc 1994).

\section{Zusammenfassung}

Einfluss des Wetters auf Fütterungsverhalten,

Nestlingswachstum und Brutüberleben von

Wendehälsen Jynx torquilla

Obwohl die Zerstörung der Bruthabitate der wichtigste Grund für den Rückgang des Wendehalses Jynx torquilla sein dürfte, spielen Wettereinflüsse möglicherweise auch eine Rolle. In dieser Studie untersuchten wir den Einfluss von Temperatur und Regenmenge auf das Fütterungsverhalten, Nestlingswachstum und Brutüberleben einer Wendehalspopulation aus den Schweizer Alpen. Wir zeichneten die Fütterungsfrequenzen und das Wachstum der Nestlinge von 17 Bruten auf, und werteten den Erfolg von 181 Bruten aus dem Zeitraum von 2002 bis 2006 aus. Die mittlere Fütterungsfrequenz betrug 7.9 Fütterungen pro Stunde; sie nahm mit zunehmender Temperatur und Nestlingsalter zu. Das Wachstum von Gewicht, Tarsus und der 8. Handschwinge war nicht stark vom Wetter beeinflusst. Gegen das Ende der Wachstumsperiode wuchsen Nestlinge, die schon schwer oder gross waren, weniger schnell, als Nestlinge, die noch leicht oder klein waren. Dies ist ein Hinweis auf kompensatorisches Wachstum. Die täglichen Überlebensraten der Bruten nahmen im Verlaufe der Saison und mit zunehmender Regenmenge ab, und sie nahmen mit zunehmendem Nestlingsalter und steigender Temperatur zu. Unsere Auswertung zeigt, dass der Einfluss von schlechtem Wetter auf Fütterungsfrequenz, Wachstum und Brutüberleben komplex ist, weil er mit dem Alter der Nestlinge ändert und möglicherweise auch die Dauer des Schlechtwetterereignisses eine Rolle spielt.

Acknowledgments We like to thank Samuel Ehrenbold, Jacques Laesser, Fabio Leippert, Paul Mosimann, Thomas Reichlin, Antoine Sierro, Aline Tagmann-Ioset and Nadja Weisshaupt for assistance in the field, Louis-Felix Bersier for renting us the video equipment, and Thomas Friedl and two reviewers for valuable comments on the manuscript. The field-work was performed respecting Swiss laws and with the necessary licences.

\section{References}

Anderson KE, Munger JC (2003) Effect of temperature on brood relocation in Pogonomyrmex salinus (Hymenoptera: Formicidae). West N Am Nat 63:122-128

Bitz A, Rohe W (1992) Der Einfluss der Witterung auf den Nahrungseintrag des Wendehalses (Jynx torquilla). Beitr Landespf Rheinland-Pfalz 15:575-591

Bitz A, Rohe W (1993) Nahrungsökologische Untersuchungen am Wendehals (Jynx torquilla) in Rheinland-Pfalz. Beih Veröff Naturschutz u Landschaftspflege Baden-Württ 67:83-100

Burnham KP, Anderson DR (2002) Model selection and multimodel inference. Springer, New York

Dinsmore SJ, White GC, Knopf FL (2002) Advanced techniques for modeling avian nest survival. Ecology 83:3476-3488

Ehrenbold S (2004) Habitat suitability modelling and components of reproductive success in the Wryneck Jynx torquilla. Master thesis, University of Bern, Switzerland

Freitag A (1996) Le régime alimentaire du Torcol fourmilier (Jynx torquilla) en Valais (Suisse). Nos Oiseaux 43:497-512

Freitag A (1998) Analyse de la disponibilité spatio-temporelle des fourmis et des stratégies de fourragement du torcol fourmilier (Jynx torquilla L.). PhD thesis, Université de Lausanne, Switzerland

Freitag A, Martinoli A, Urzelai J (2001) Monitoring the feeding activity of nesting birds with an autonomous system: case study of the endangered Wryneck Jynx torquilla. Bird Study 48:102-109

Glutz von Blotzheim UN, Bauer KM (1980) Handbuch der Vögel Mitteleuropas. Bd. 9. Columbiformes-Piciformes. Akademische Verlagsgesellschaft, Wiesbaden

Hafner H, Dugan PJ, Kersten M, Pineau O, Wallace JP (1993) Flock feeding and food-intake in little egrets Egretta garzetta and their effects on food provisioning and reproductive success. Ibis 135:25-32

Hölzinger J (1992) Zur Nestlingsnahrung des Wendehalses (Jynx torquilla). Beih Veröff Naturschutz u Landschaftspflege BadenWürtt 66:47-50

Keller LF, van Noordwijk AJ (1994) Effects of local environmental conditions on nestling growth in the great tit Parus major L. Ardea 82:349-362

Lepczyk CA, Karasov WH (2000) Effect of ephemeral food restriction on growth of house sparrows. Auk 117:164-174 
Menzel H (1968) Der Wendehals (Jynx torquilla). Ziemsen, Wittenberg

Monk JF (1963) The past and present status of the Wryneck in the British Isles. Bird Study 10:112-132

Nagy LR, Holmes RT (2004) Factors influencing fecundity in migratory songbirds: is nest predation the most important? J Avian Biol 35:487-491

Pranschke AM, Hooper-Bùi LM (2003) Influence of abiotic factors on red imported fire ant (Hymenoptera: Formicidae) mound population ratings in Louisiana. Environ Entomol 32:204-207

R Development Core Team. 2004. R: a language and environment for statistical computing. R Foundation for Statistical Computing, Vienna

Radford AN, McCleery RH, Woodburn RJW, Morecroft MD (2001) Activity patterns of parent Great Tits Parus major feeding their young during rainfall. Bird Study 48:214-220

Sæther BE, Bakke O (2000) Avian life history variation and contribution of demographic traits to the population growth rate. Ecology 81:642-653

Sæther BE, Engen S, Möller AP, Matthysen E, Adriaensen F, Fiedler W, Leivits A, Lambrechts MM, Visser ME, Anker-Nilssen T, Both C, Dhondt AA, McCleery RH, McMeeking J, Potti J, Röstad OW, Thomson D (2003) Climate variation and regional gradients in population dynamics of two hole-nesting passerines. Proc R Soc Lond B 270:2397-2404

Sæther BE, Sutherland WJ, Engen S (2004) Climate influences on avian population dynamics. Adv Ecol Res 35:185-209
Schaub M, Kania W, Köppen U (2005) Variation of primary production during winter induces synchrony in survival rates in migratory white storks Ciconia ciconia. J Anim Ecol 74:656-666

Scherner ER (1989) Wendehals und Populationsbiologie—der "Vogel des Jahres 1988" und die Pflicht zur Forschung. Laufener Seminarbeitr 3/89:24-39

Seifert B (1996) Ameisen: beobachten, bestimmen. Naturbuch, Augsburg

Siikamäki P (1996) Nestling growth and mortality of Pied Flycatchers Ficedula hypoleuca in relation to weather and breeding effort. Ibis 138:471-478

Stearns SC (1992) The evolution of life histories. Oxford University Press, Oxford

Sutter E (1941) Beitrag zur Kenntnis der postembryonalen Entwicklung des Wendehalses (Jynx t. torquilla L.). Schweiz Archiv Ornithol 1:481-508

Tomialojc L (1994) Wryneck. In: Tucker MG, Heath MF (eds) Birds in Europe: their conservation status. BirdLife International, Cambridge, pp 342-343

Veistola S, Lehikoinen E, Eeva T (1997) Weather and breeding success at high latitudes-the Pied Flycatcher Ficedula hypoleuca and the Siberian Tit Parus cinctus. Ornis Fenn 74:89-98

Walther GR, Post E, Convey P, Menzel A, Parmesan C, Beebee TJC, Fromentin JM, Hoegh-Guldberg O, Bairlein F (2002) Ecological responses to recent climate change. Nature 416:389-395

White GC, Burnham KP (1999) Program MARK - survival estimation from populations of marked animals. Bird Study 46:120-139 